Acta Horticulturae et Regiotecturae - Special Issue

Nitra, Slovaca Universitas Agriculturae Nitriae, 2021, pp. 12-15

\title{
ASSESSMENT OF A YIELD PREDICTION METHOD BASED ON TIME SERIES LANDSAT 8 DATA
}

\author{
Andrea SZABÓ*, Odunayo David ADENIYI, János TAMÁS, Attila NAGY \\ University of Debrecen, Hungary
}

\begin{abstract}
The active biomass of cultivated plants and average yield decreases as a result of biotic and abiotic stress effect. The extent of the reduction can be quantified on the basis of remotely sensed data. The aim of this research is to evaluate the suitability of Landsat 8 data for a wheat yield estimation. We processed Landsat 8 recordings for the period 2013-2019 and generated NDVI data. Time series NDVI data were calibrated and validated with observed wheat yield averages. The agricultural plots around Karcag, Hungary, were our research area. The relation between Landsat NDVI data and yield was strongest and highest in the total biomass period $\left(R^{2}=0.53-0.54\right)$ and the estimation error based on RMSE is between 0.48-0.7 t.ha ${ }^{-1}$.
\end{abstract}

Keywords: Landsat 8, crop, yield prediction

There has been an increase in the concern about food security and sustainable agricultural development in the world today, of which the actual estimation of supply and demand of major crops such as wheat is the main component. Wheat is the third most grown cereal after maize and rice with a production of 3.78 t.ha $^{-1}$ globally (FAOSTAT, 2018). In Hungary, the temperature keeps increasing and this can be characterized by a decrease in precipitation and an increasing frequency of droughts (Szász, 2005). For this reason, monitoring the agricultural areas is essential. Remote sensing-based agricultural monitoring systems are able to provide timely information on the status, phases and expected yields of crop production (Bolton, Friedl, 2013; Tewkesbury et al. 2015; Vicente-Serrano et al., 2015), complementing the traditional methodology (Atzberger, 2013; Tamás, Nagy, Fehér, 2015; Nagy, Fehér, Tamás, 2018). This is important because the farmers can easily identify areas where changes in crop yields are expected (Clement et al., 2013). We aim to analyse and apply a yield estimation monitoring system based on Normalized Difference Vegetation Index (NDVI) data derived from Landsat 8 satellite imagery. The interest in using satellite remote sensed data for crop monitoring and crop production forecasting today has tremendously increased due to its potential to produce data synoptically, with much spatial coverage, potentially at global scale. Moreover, remote sensing is capable of providing timely (and potentially real-time) and objective data on crop growth at relatively small cost. We have calculated the NDVI and developed a model to monitor a crop yield. The NDVI as an indicator of photo synthetically active vegetation provides important information for farmers, as the value obtained correlates with the specific chlorophyll content and biomass content of the vegetation covering in the area (Bolton, Friedl, 2013; Panda, Ames, Panigrahi, 2010; Dempewolf et al., 2014; Mkhabela et al., 2011; De la Casa et al., 2018).

\section{Material and method}

We have processed satellite images prepared by Landsat $8 \mathrm{OLI}$, from which we have calculated the time series NDVI data of the area and compared to the real yield averages for the period 2013-2019, for our research. The Landsat 8 satellites orbit the Earth in a 16-day repetition cycle. Landsat captures approximately 740 scenes every 8 days on the Worldwide Reference System-2 (WRS-2) sequence system with a scene size of $185 \times 180 \mathrm{~km}$. Landsat $8 \mathrm{OLI} /$ TIRS C1 Level-1 images with a cloud covering less than $50 \%$ were downloaded from https://earthexplorer.usgs. gov/. The downloaded files contain a total of 11 spectral bands at different wavelengths of visible, near-infrared and shortwave infrared, of which the data of B4 (red) and B5 (NIR) bands with $30 \mathrm{~m}$ spatial resolution were used for further processing in this study. The first calculation of the NDVI index (1) was performed in ArcGIS software with Raster Calculator according to the following formula.

$$
N D V I=(N I R-R E D) /(N I R+R E D)
$$

The average yield data $\left({\left.\mathrm{t} . h \mathrm{a}^{-1}\right)}\right.$ required for the research were provided by the Karcag Research Institute of Agriculture in Hungary. Wheat yield data from 16 arable lands (Figure 1) for the period 2013-2019 were used to calibrate the time

Contact address: Andrea Szabó, University of Debrecen, Faculty of Agricultural and Food Sciences and Environmental Management, Institute of Water and Environmental Management, J +36 5050 84 44/880 12; e-mail: szabo.andrea@agr.unideb.hu, 


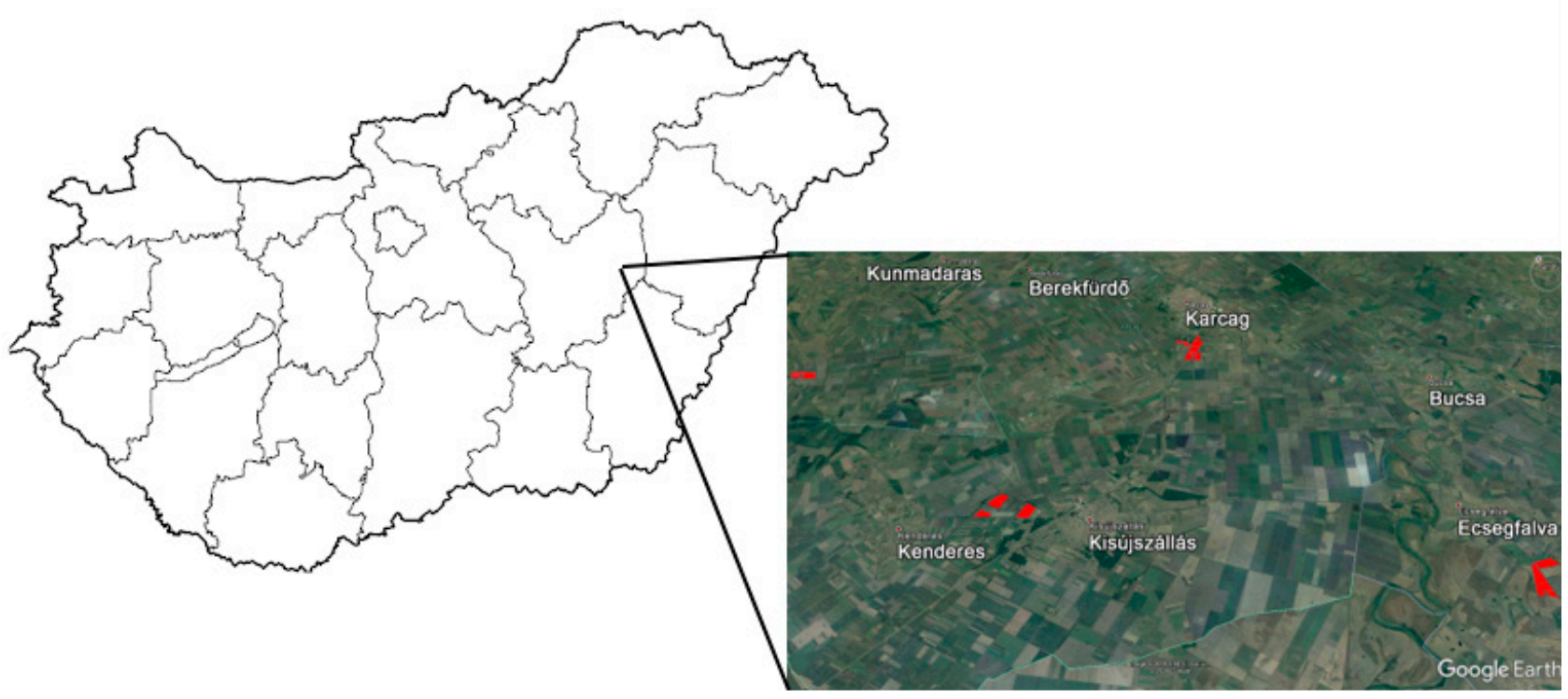

Figure 1 Location of the examined plots Source: Google Earth

series NDVI data derived from Landsat $8 \mathrm{OLI}$ and to validate the prepared model.

The research institute has provided us with the average yields of real wheat harvested/plot and a vector database of an arable land. We have performed the additional necessary calculations in the ArcGIS software environment. In the first step, we selected the mean NDVI values for each plot between March and August. The resulting average NDVI values/plot were calibrated with the actual yield average data. The calibration was performed by a linear regression (2) and we calculated the deterministic coefficient and estimation equations, the RMSE (Root Mean Square Error) (3) and NRMSE (Normalized Root Mean Square Error) (4) values were calculated to analyse the reliability of the regression and to validate the estimation equations. The calibration was based on data from the first 6 years (2013-2018), while the validation was based on data from 2018-2019, similarly to the research of Dempewolf et al. (2014) and Nagy, Fehér, Tamás (2018), where a minimum of 6-year remotely sensed time series were used for the yield analysis. In addition, we calculated the relative (5) and absolute (6) deviations of the estimated value from the actual harvested value.

$$
\begin{gathered}
R^{2}=1-\frac{\sum_{i=1}^{n}\left(y_{i}-y_{i}^{\prime}\right)^{2}}{\sum_{i=1}^{n}\left(y_{i}-\bar{y}\right)^{2}} \\
R M S E=\sqrt{\frac{\sum_{i=1}^{n}\left(y_{i}-y_{i}^{\prime}\right)^{2}}{n}} \\
N R M S E=\sqrt{\frac{\sum_{i=1}^{n}\left(y_{i}-y_{i}^{\prime}\right)^{2} / /\left(\max \left(y_{i}\right)-\min \left(y_{i}\right)\right)}{n}}
\end{gathered}
$$

$$
\begin{aligned}
& \text { Relative deviation }=\frac{y_{i}^{\prime}-y_{i}}{\bar{y}} \cdot 100 \\
& \text { Absolute deviation }=\left|\frac{y_{i}^{\prime}-y_{i}}{\bar{y}} \cdot 100\right|
\end{aligned}
$$

where:

$y_{i} \quad$ - data measured on the sample (t.ha $\left.{ }^{-1}\right)$

$y_{i}^{\prime} \quad$ - estimated yield of the sample $\left(\right.$ t.ha $\left.^{-1}\right)$

- average yield (t.ha ${ }^{-1}$ )

$n \quad-$ number of samples (t.ha ${ }^{-1}$ )

\section{Results and discussion}

Based on the results of the linear regression, the deterministic coefficient values calculated on the basis of the NDVI values at the end of May and the first half of June period have a stronger correlation (Figure 2) with the yield averages (on days $150,154,160$ and 163 ). It is noteworthy that the NDVI data on days 154 and 160 showed the strongest relation with the yield averages $\left(R^{2}=0.542\right.$ and $\left.R^{2}=0.536\right)$ (Figure 2 ).

After calculating the estimation models, we validated the models based on the relative deviation, absolute deviation, RMSE and NRMSE\% values based on the NDVI and yield data of period 2018-2019. The RMSE and NRMSE\% values for the years are shown in the Table 1. The validated 2-year mean RMSE was 0.713 t.ha $^{-1}$ on day $150,0.547$ t.ha $^{-1}$ on day $154,0.489$ t.ha ${ }^{-1}$ on day 160 , and 0.491 t.ha $^{-1}$ on day 163. The mean NRMSE (\%) values based on 2 validated years were $13.09 \%$ on day $150,10.04 \%$ on day $154,8.99 \%$ on day 160 , and $9.01 \%$ on day 163 .

The relative deviation of the forecast value from fair values was $-6.87 \%$ on day 150 , on day 154 it was $-5.05 \%$, on day 160 it was $-5.06 \%$, and on day 163 it was $-5.31 \%$. Concerning the absolute differences, the difference on day 150 was $8.37 \%$, on day 154 it was $7.51 \%$, on day 160 it was $6.35 \%$ and on day 163 it was $6.14 \%$ (Figure 3). 

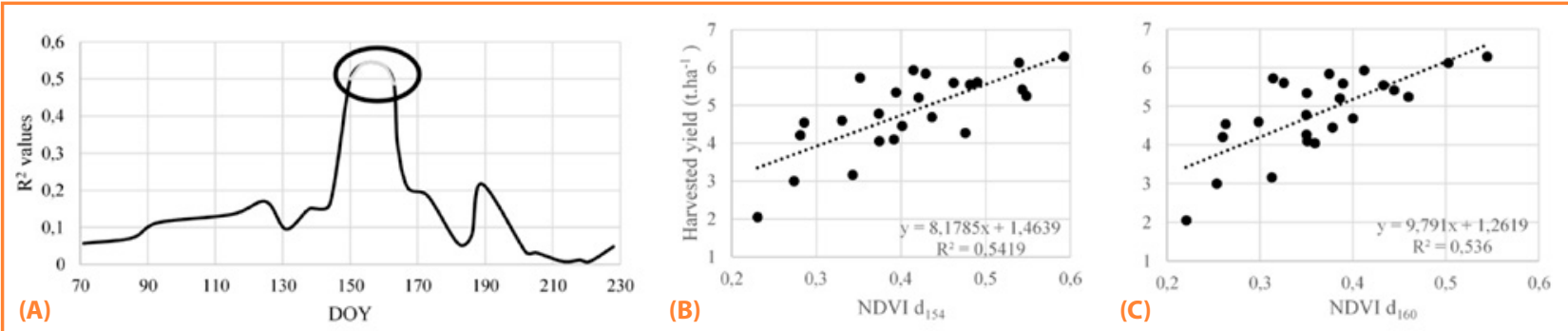

Figure 2 Determination coefficients of NDVI versus yield (A) and linear regression of NDVI and yield on days 154 (B) and 160 (C)

Table 1 Yield estimation models from 2018 to 2019

\begin{tabular}{|c|c|c|c|c|}
\hline Day & Equation & Year & RMSE & NRMSE (\%) \\
\hline \multirow{2}{*}{150.} & \multirow{2}{*}{$y=9.5592 \cdot \mathrm{NDVI}_{150}+0.792$} & 2018 & 0.865 & 15.87 \\
\hline & & 2019 & 0.519 & 9.54 \\
\hline \multirow{2}{*}{154.} & \multirow{2}{*}{$y=8.1785 \cdot \mathrm{NDVI}_{154}+1.4639$} & 2018 & 0.455 & 8.35 \\
\hline & & 2019 & 0.626 & 11.49 \\
\hline \multirow{2}{*}{160.} & \multirow{2}{*}{$y=9.791 \cdot \mathrm{NDVI}_{160}+1.2619$} & 2018 & 0.439 & 8.07 \\
\hline & & 2019 & 0.535 & 9.82 \\
\hline \multirow{2}{*}{163.} & \multirow{2}{*}{$y=9.1427 \cdot \mathrm{NDVI}_{163}+1.7047$} & 2018 & 0.401 & 7.36 \\
\hline & & 2019 & 0.566 & 10.39 \\
\hline
\end{tabular}

Based on the relative differences, it can be stated that the predicted yield values are just slightly smaller that the measured yield values. The values of the absolute deviation were not much

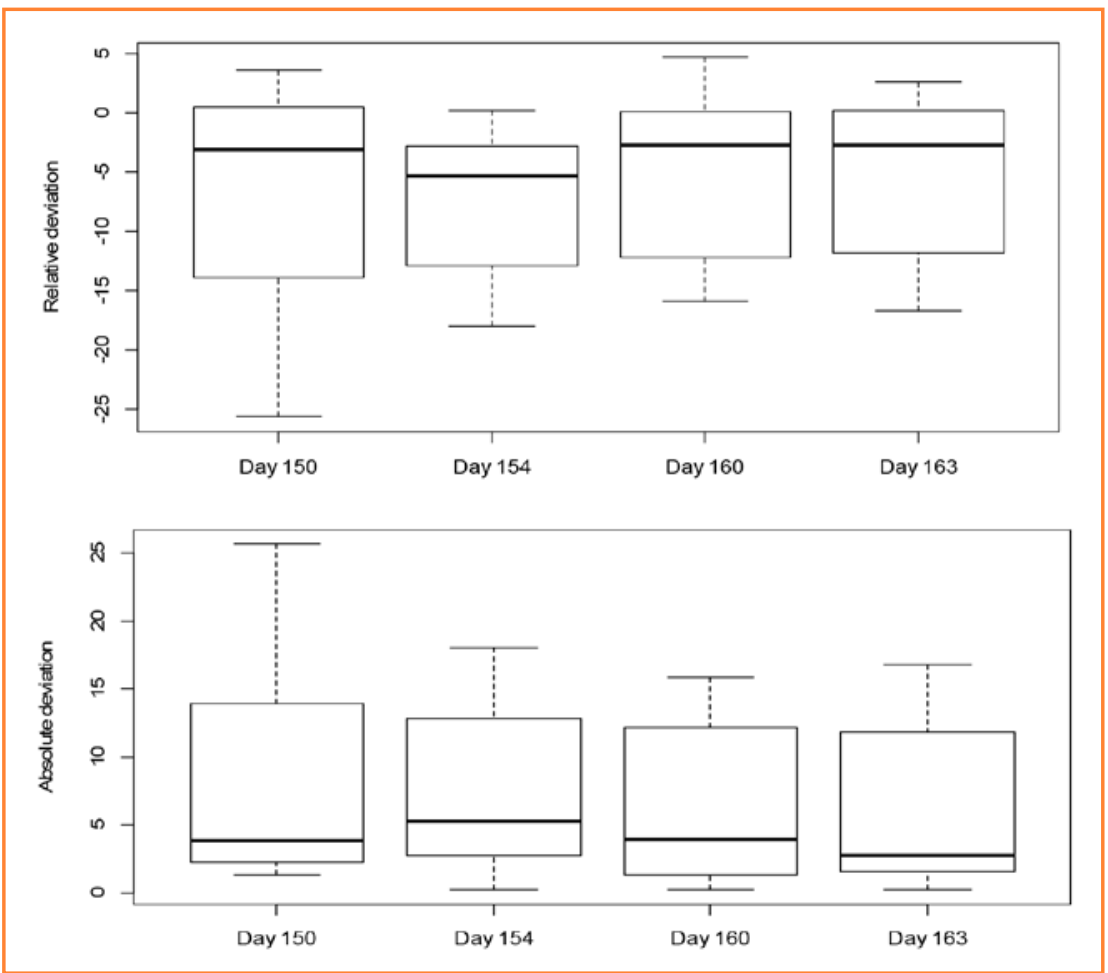

Figure 3 Relative and absolute deviations of the predicted value from the actual values higher than the $5 \%$ threshold accepted in the literature (Ferencz et al., 2004). The closest to the $5 \%$ threshold was the $160^{\text {th }}$ day with the highest $R^{2}$, which differed barely by $1 \%$. 


\section{Acknowledgments}

We thank for providing us with wheat yield data from the Agricultural Research Institutes and the Karcag Research Institute of the University of Debrecen. The research was supported by the project EFOP-3.6.2-16-2017-00001 Research on Complex Rural Economic and Sustainability Developments, Development of its Service Network in the Carpathian Basin.

\section{References}

Atzberger, C. (2013). Advances in remote sensing of agriculture: context description, existing operational monitoring systems and major information needs. Remote Sens., 5, 949-981.

Bolton, D. K., Friedl, M. A. (2013). Forecasting crop yield using remotely sensed vegetation indices and crop phenologymetrics. Agric. For. Meteorol., 173, 74-84.

Clement, S., Lassman, F., Barley, E., Evans-Lacko, S., Williams, P., Yamaguchi, S., Slade, M., Rüsch, N., Thornicroft, G. (2013). Mass media interventions for reducing mental health-related stigma (Review). The Cochrane Library, (7).

De la Casa, A., Ovando, G., Bressanini, L., Martínez, J., Díaz, G., Miranda, C. (2018). Soybean crop coverage estimation from NDV images with different spatial resolution evaluate yield variability in a plot. ISPRS J. Photogramm. Remote Sens., 146, 531-547.

Dempewolf, J., Adusei, B., Becker-Reshef, I., Hansen, M., Potapov, P., Khan, A., Barker, B. (2014). WheatyieldforecastingforPunjabProvincefromvegetation index time series and historic crop statistics. Remote Sens., 6, 9653-9675. FAOSTAT (2018). website. http://www.fao.org/faostat/en/\#data/ QC/ Query date: 2020.05.

Ferencz, Cs., Bognár, P., Lichtenberge, J., Hamar, D., Tarcsai, GY., Timár, G., Molnár, G., Pásztor, Sz., Steinbach, P., Székely, B., Ferencz, O. E., Ferencz-Árkos, I. (2004). Crop yield estimation by satellite remote sensing. Int. J. Remote Sens., 25(20), 4113-4149.

Labus, M. P., Nielsen, G. A., Lawrence, R. L., Engel, R., Long, D. S. (2002). Wheat yield estimates using multi-temporal NDVI satellite imagery. International Journal of Remote sensing, 23(20), 4169-4180.
Marti, J., Bort, J., Slafer, G. A., Araus, J. L. (2007). Can wheat yield be assessed by early measurements of normalized difference vegetation index? Annals of Applied Biology, 150, 253-257.

Mkhabela, M. S., Bullock, P., Raj, S., Wang, S., Yang, Y. (2011). Crop yield forecasting on the Canadian Prairies using MODIS NDVI data. Agric. For. Meteorol., 151, 385-393.

Nagy, A., Fehér, J., Tamás, J. (2018).Wheat and maize yield forecasting for the Tisza river catchment using MODIS NDVI time series and reported crop statistics. Computers and Electronics in Agriculture, 151, 41-49.

Panda, S. S., Ames, D. P., Panigrahi, S. (2010). Application of vegetation indices for agricultural crop yield prediction using neural network techniques. Remote Sens., 2, 673-696.

Szász, G. (2005). Termésingadozást kiváltó éghajlati változékonyság a Kárpát-medencében. "Agro-21" füzetek, (40) 33-69.

Tamás, J., Nagy, A., Fehér, J. (2015). Agricultural biomass monitoring on water sheds based on remotely sensed data. Water Science and Technology, 72(12), 2212-2220.

Tewkesbury, A. P., Comber, A. J., Tate, N. J., Lamb, A., Fisher, P. F. (2015). A critical synthesis of remotely sensed optical image changed detection techniques. Remote Sensing of Environment, 160, 1-14.

Tiecheng, B., Nannan, Z., Benoit, M., Youqi, C. (2019). Jujube yield prediction method combining Landsat 8 Vegetation Index and the phenological length. Computers and Electronics in Agriculture, 162, 1011-1027.

Vicente-Serrano, S. M., Cabello, D., Tomás-Burguera, M., MartínHernández, N., Beguería, S., Azorin-Molina, C., Kenawy, A. E. (2015). Droughtvariability and land degradation in semiarid regions: assessment using remote sensing data and drought indices (19822011). Remote Sens., 7, 4391-4423. 